ENCYCLOPEEDE Encyclopédie berbère

BERBERE

$27 \mid 2005$

27 | Kairouan - Kifan Bel-Ghomari

\title{
Kef el-Damous
}

(ou Kel el-Kherraz)

\section{G. Lefebvre}

\section{OpenEdition}

\section{Journals}

Édition électronique

URL : http://journals.openedition.org/encyclopedieberbere/1326

ISSN : 2262-7197

\section{Éditeur}

Peeters Publishers

Édition imprimée

Date de publication : 1 août 2005

Pagination : 4126-4127

ISBN : 2-7449-0538-0

ISSN : 1015-7344

Référence électronique

G. Lefebvre, «Kef el-Damous », Encyclopédie berbère [En ligne], 27 | 2005, document K34, mis en ligne le 01 juin 2011, consulté le 24 septembre 2020. URL : http://journals.openedition.org/ encyclopedieberbere/1326

Ce document a été généré automatiquement le 24 septembre 2020

(C) Tous droits réservés 


\title{
Kef el-Damous
}

\author{
(ou Kel el-Kherraz)
}

\section{G. Lefebvre}

\section{Station de gravures rupestres de la région de Constantine}

1 À $12 \mathrm{~km}$ au nord-ouest de Sedrata et toute proche de la célèbre station de Kef-elM'saoura, Kef el-Damous est un rocher percé d'une grotte profonde qui sert actuellement d'écurie aux habitants de la mechta construite à proximité. Selon eux, ce lieu s'est toujours appelé Kef el-Damous, alors qu'il est connu dans la littérature sous le nom de Kef el-Kherraz, ou de Damous el-Kherraz.

2 À l'entrée de la grotte, la paroi du rocher est gravée de dessins très stylisés qui rappellent des caractères d'écriture. Malheureusement, un bloc énorme, détaché récemment de la voûte, a complètement détruit dans sa chute la moitié des gravures situées vers l'extérieur.

3 La station a été étudiée par R. Bernelle en 1892, St. Gsell en 1911, M. Solignac en 1928 et nous-même en 1967.

4 Nous avons relevé 13 mouflons stylisés, 1 signe incompréhensible et, datant d'une époque plus récente, un animal indéterminé.

5 Les mouflons et le signe ont été obtenus par un trait recti-curviligne poli, sans piquetage préalable. Les surfaces sont entièrement passées à l'ocre rouge. L'animal indéterminé a été réalisé par martelage de la surface.

6 Il semble que les mouflons stylisés et le signe soient préhistoriques, tandis que l'animal gravé par martelage apparaît vraisemblablement protohistorique ou historique. 
Gravures du Damous el Kherraz (Kef el Damous). D’après M. Solignac.

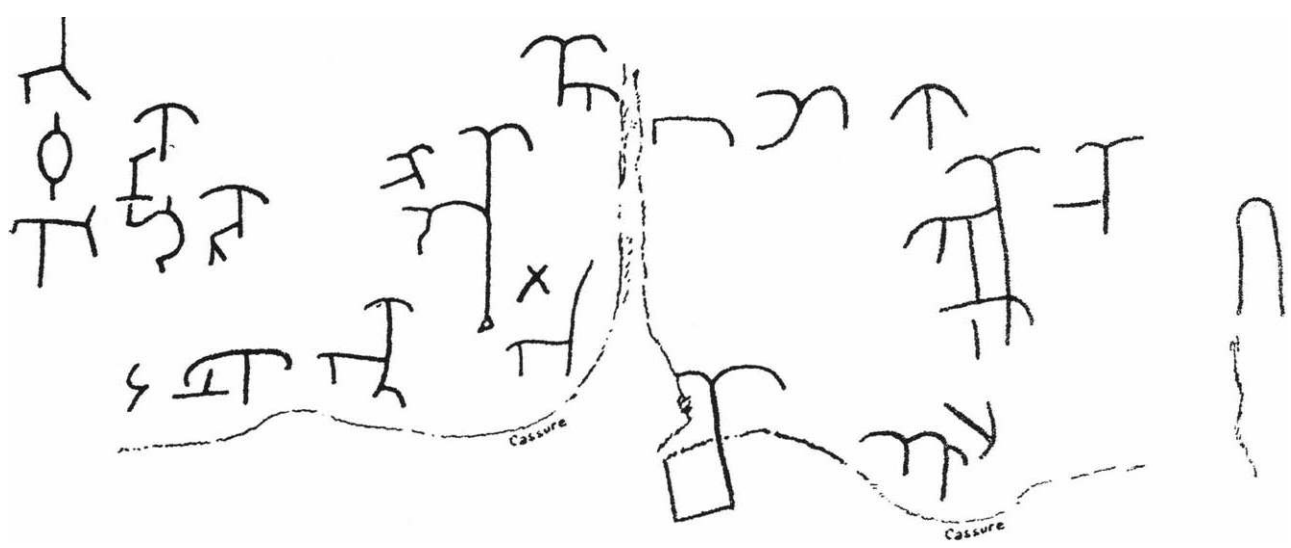

Gravures subsistantes après la chute du bloc de droite. D'après $\mathrm{G}$. Lefebvre.

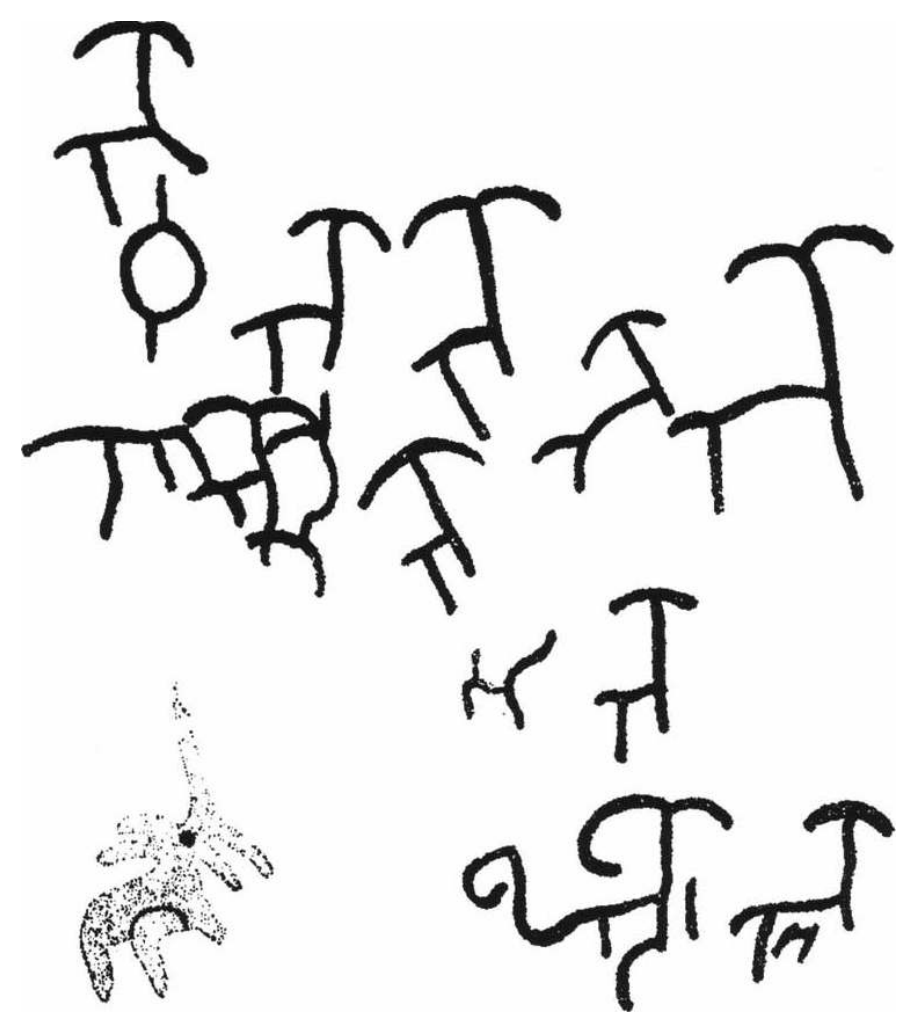

7 À cause de la répétition du même motif, à cause aussi de l'emploi de l'ocre rouge, on peut penser que les figurations stylisées de mouflons ont une signification magique ou religieuse.

L'interprétation des figurations stylisées a été malaisée : on y a vu successivement des inscriptions libyques (Bernelle), des caractères d'écriture n'appartenant pas à un alphabet des temps historiques (Gsell), des personnages (Solignac). Chaque représentation, lorsqu'elle est complète, se compose d'un corps formé d'un trait légèrement arqué, de deux pattes représentées par deux traits légèrement verticaux, d'un petit bout de queue qui n'est souvent que le prolongement au-delà de la patte arrière de la ligne du corps; la ligne de la patte avant se prolonge au-dessus du corps pour former le cou et la tête de la bête ; deux lignes courbes dessinent les cornes (pour cinq mouflons, un seul trait courbe repose en son milieu sur la ligne du cou pour 
évoquer les cornes). Ce schématisme est tel qu'on a pu hésiter longtemps entre dessin et caractère d'écriture mais il s'agit bien de représentations animales et plus précisément de mouflons.

\section{BIBLIOGRAPHIE}

BERNELLE R., Vestiges antiques de la commune mixte de l'Oued Cherf. Rec. des Not. et Mém. de la Soc. archéol. du dép. de Constantine, t. XXVII, 1892, p. 54-113 (p. 100-101 et fig. 3).

GSELL St., Atlas archéologique de l'Algérie, Alger, Jourdan, 1911, feuille de Souk-Ahras, nº 225.

SOLIGNAC M., Les Pierres écrites de la Berbérie orientale (Est Constantinois et Tunisie). Tunis, Barlier, 1928, p. 119-123.

LEFEBVRE G. et L., Corpus des gravures et des peintures de la région de Constantine. Mém. VII du CRAPE, Paris, AMG, 1967, p. 223-225.

INDEX

Mots-clés : Art rupestre, Protohistoire 